\title{
Os efeitos da suplementação de creatina em praticantes de treinamento resistido -
}

\section{Uma revisão de literatura}

\author{
The Effects of Creatine Supplementation in Resistance Trainers - A Literature Review \\ Los efectos de la suplementación con creatina en los entrenadores de resistencia: Una revisión de la
}

\author{
Givanildo de Oliveira Santos \\ ORCID: https://orcid.org/0000-0001-5279-1535 \\ Faculdade de Mauá Brasília, Brasil \\ E-mail: givanildo-o@hotmail.com \\ Pedro Bruno Nascimento Furquim Cruvinel \\ ORCID: https://orcid.org/0000-0002-6707-9708 \\ Faculdade de Mauá Brasília, Brasil \\ E-mail: pedrobruno27@gmail.com \\ Marcelo Bruno Lima Pereira \\ ORCID: https://orcid.org/0000-0003-0457-5939 \\ Faculdade de Mauá Brasília, Brasil \\ E-mail: marcelobrunoedf@gmail.com \\ Daiany Neves da Silva \\ ORCID: https://orcid.org/0000-0002-0098-1510 \\ Faculdade de Mauá Brasília, Brasil \\ E-mail: daianynevesledfit@gmail.com \\ Luciano Lima dos Santos \\ ORCID: https://orcid.org/0000-0001-7683-5969 \\ Faculdade de Piracanjuba, Brasil \\ E-mail: luciano.edfisica@ hotmail.com \\ Raquel Borges de Souza \\ ORCID: https://orcid.org/0000-0003-1675-6649 \\ Faculdade de Piracanjuba, Brasil \\ E-mail: raquelsab1980@gmail.com \\ Sebastião Lobo da Silva \\ ORCID: https://orcid.org/0000-0003-2639-0898 \\ Universidade Católica de Brasília, Brasil \\ E-mail: slobo2011@gmail.com
}

\begin{abstract}
Resumo
O consumo de creatina pode potencializar os efeitos do treinamento resistido promovendo resultados fisiológicas que podem interferir de forma positiva, gerando o aumento de força muscular, hipertrofia muscular e resistência. Este artigo objetivou verificar os principais efeitos e os benefícios da suplementação de creatina em praticantes de treinamento resistido. Quanto aos métodos para a elaboração deste, buscou-se a revisão de literatura, qualitativa, de caráter descritivo, a partir de documentos secundários para o alcance do objetivo. Conclui-se que a suplementação de creatina por praticantes de treinamento resistido, poderá influenciar nos resultados fisiológicos de tal maneira a melhorar a força muscular, a hidratação celular, o aumento de massa muscular e a resistência muscular.
\end{abstract}

Palavras-chave: Nutrição esportiva; Musculação; Academias; Exercícios físicos; Saúde.

\begin{abstract}
Creatine consumption can enhance the effects of resistance training, promoting physiological results that can interfere in a positive way, generating an increase in muscle strength, muscle hypertrophy and endurance. This article aimed to verify the main effects and benefits of creatine supplementation in resistance training practitioners. As for the methods for its elaboration, we sought to review the literature, qualitative, descriptive, from secondary documents to achieve the objective. It is concluded that creatine supplementation by resistance training practitioners may influence the physiological results in such a way as to improve muscle strength, cell hydration, increase in muscle mass and muscle endurance.
\end{abstract}

Keywords: Sports nutrition; Bodybuilding; Gyms; Physical exercises; Health.

\section{Resumen}

El consumo de creatina puede potenciar los efectos del entrenamiento de resistencia, promoviendo resultados fisiológicos que pueden interferir de forma positiva, generando un aumento de la fuerza muscular, hipertrofia 
muscular y resistencia. Este artículo tuvo como objetivo verificar los principales efectos y beneficios de la suplementación con creatina en practicantes de entrenamiento de resistencia. En cuanto a los métodos para su elaboración, se buscó revisar la literatura, cualitativa, descriptiva, a partir de documentos secundarios para lograr el objetivo. Se concluye que la suplementación con creatina por parte de los practicantes de entrenamiento de resistencia puede influir en los resultados fisiológicos de tal manera que mejore la fuerza muscular, la hidratación celular, el aumento de masa muscular y la resistencia muscular.

Palabras clave: Nutrición deportiva; Culturismo; Gimnasios; Ejercicio físico; Salud.

\section{Introdução}

O corpo produz em média um grama de creatina de forma endógena ao dia, ocorrendo a síntese nos pâncreas, rins e fígado. No entanto, o restante da creatina necessária para o corpo é adquirido através da alimentação, em específicos carnes vermelhas, e alimentos de origem animais. Este consumo para a complementação do estoque de creatina para o corpo, deverá ocorrer em média um grama ao dia através da alimentação, a creatina armazenada no corpo humano com a maior proporção em média 95\% nos músculos esqueléticos, e o restante de 5\% no cérebro, rins, fígado e testículos (Persky \& Brazeau, 2001).

Pessoas com dietas vegetarianas possuem menor consumo deste aminoácido que poderá influenciar em atividades diárias, porque maior concentração de creatina está em alimentos de origem animal (Burke, et al., 2008). A suplementação com creatina tem sido investigada em estudos de patologias, distúrbios, e principalmente como recurso ergogênico na melhora do desempenho físico, e de performance de atletas e praticantes de exercícios físicos (Buford, et al., 2007).

Conforme Volek e Kraemer (1996), quando houve o consumo por praticantes de exercícios físicos os resultados foram melhorados no desempenho físico, aumento da massa muscular e redução de gordura. Os efeitos ergogênicos da creatina são conhecidos devido ao desempenho durante os exercícios físicos, como: força muscular explosiva e aumento da massa corporal magra em exercícios de resistidos (Burke, et al., 2008). Alguns estudos relatam que o consumo de creatina está relacionado a recuperação de danos musculares após o exercício excêntrico, sendo indicada a suplementação de creatina para melhorar a força máxima e inibir a liberação de CK devido ao exercício de alta intensidade (Cooke, et al., 2009).

Objetivou-se neste estudo, verificar os principais efeitos e os benefícios da suplementação de creatina em praticantes de treinamento resistido em diferentes idades.

\section{Metodologia}

De acordo com Estrela (2018), a presente pesquisa trata-se de uma revisão bibliográfica de natureza qualitativa, para o levantamento bibliográfico foram utilizados artigos científicos disponíveis online. As buscas dos artigos foram realizadas nas plataformas de pesquisas: PubMed, Lilacs, Google acadêmico, MedLine, ScienceDirect, SciELO, ScienceDirect e Elsevier, no período de agosto/2020 a janeiro/2021. Este artigo consiste em uma revisão de literatura, de caráter qualitativa descritiva, integrando estudos já concluídos e realizando uma discussão a partir dos resultados encontrados, tendo critérios de inclusão e exclusão. Para a inclusão de artigos na pesquisa, foi definida as amostras, obedecendo aos seguintes critérios: publicações em português e em inglês que abordaram a temática, atendendo as palavras-chave: "creatina", "suplementos alimentares", "treinamento resistido e suplementação", que utilizaram algum percurso metodológico de pesquisa experimental em protocolos avaliados com a suplementação e a prática de treinamento resistido.

\section{Revisão}

\subsection{Creatina}

A creatina é um composto sintetizado a partir de três aminoácidos (glicina, arginina e metionina) e três enzimas (Larginina: glicina amidinotransferase, guanidinoacetato metiltransferase e metionina adenosiltransferase). A síntese de arginina 
e glicina ocorrem nos rins e as etapas subsequentes envolvendo metionina no fígado. A creatina poderá ser consumida na dieta através de alimentos oriundos, principalmente de bovinos, suínos e peixes (Wyss \& Kaddurah-daouk, 2000).

A creatina monoidratada está entre os suplementos nutricionais comumente mais consumidos por atletas e praticantes de exercícios físicos, são consumidos com o objetivo de preservar ou aumentar a massa muscular e a força muscular em adultos mais velhos (Kreider, et al., 2017). A creatina poderá atuar na hidratação da célula muscular, aumentando a água por osmose, podendo ativar a síntese de proteínas nas fibras musculares (Safdar, et al., 2008).

Estudos objetivando verificar os efeitos da suplementação de creatina relataram o aumento e armazenamento de creatina nas células musculares, melhorando desempenho físico durante o treinamento (Dangott, et al., 2000).

\subsection{Suplementação com creatina}

Volek, et al., (1996), estudaram o consumo de creatina, e relataram o aumento na força muscular após 12 semanas de treino resistido e suplementação. Aplicou-se o protocolo de ingestão de creatina de uma semana de 25 gramas por dia e 5 gramas durante a manutenção até completar as 12 semanas de treino resistido.

Estes efeitos ocorrem pelo aumento total de creatina no musculo, resultando em trifosfato de adenosina com maior rapidez na regeneração nos períodos de intervalos entre os treinos de resistência, desse modo, possibilitando o treino com maior intensidade e duração sem perder a qualidade do treinamento.

De acordo com Volek e Rawson (2004), a suplementação com creatina, e associado ao treino de resistência de alta intensidade melhora o desempenho físico, eleva a massa muscular e hidratação muscular. De acordo com Rawson \& Volek (2003), praticantes de treinamento resistido que ingeriram creatina, melhoraram em média $+8 \%$ e $+14 \%$ no desempenho da força máxima (1RM) ou resistência (repetições máximas em uma determinada porcentagem de 1RM), quando comparados aos grupos de placebos.

Jakobi, et al., (2000), relataram não verificar nenhum efeito de um protocolo de suplementação com creatina de curto prazo na força isométrica no exercício de flexão do cotovelo durante a ativação muscular e recuperação. Porém, este estudo não deixou a metodologia clara se a suplementação de creatina conciliada com o treinamento de resistido.

Segundo Bemben, et al., (2010), a suplementação só com creatina ou combinada com whey protein não demonstraram melhoras na força e o aumento da massa muscular em praticantes de treinamento resistido durante 14 semanas (3 dias por semana) em homens mais velhos.

Estes diferentes resultados podem ser explicados pela possibilidade que os grupos suplementados foram avaliados e a quantidade de suplementação de creatina sendo consumida somente nos dias de treinos (3 vezes por semana). Este protocolo aplicado não foi eficaz em homens de meia-idade e mais velhos, no desenvolvimento de massa muscular e força (Buford, et al., 2007).

\subsection{Creatina e hipertrofia muscular}

Cribb, et al., (2007), relataram melhores resultados em 1RM, massa muscular, área da seção transversal da fibra e proteína contrátil em jovens treinados do sexo masculino, estes suplementados e treinando treinamento de resistência contendo 0,1 grama por peso corporal de creatina, 1,5 grama por peso corporal de proteína e carboidrato e comparado com a proteína ou um suplemento de carboidrato de proteína sem creatina.

A quantidade de creatina suplementada em estudo por Cribb, et al., (2007), foi maior do que a quantidade normalmente relatada em estudos anteriores (uma dose de carga a cerca de 20 gramas por peso corporal ao dia, seguido por uma dose de manutenção de 3 a 5 gramas por peso corporal ao dia, é, geralmente equivalente a aproximadamente 0,3 gramas por peso corporal ao dia, e a duração do período de suplementação em estudos anteriores (Louis, et al., 2003). 
Burke, et al., (2008), relataram efeitos de um treinamento resistido de 8 semanas suplementado com creatina durante 7 dias, sendo o seguinte protocolo de carregamento (0,25 grama por peso corporal ao dia), posteriormente o período de manutenção de 49 dias (0,06 grama por peso corporal ao dia), em pessoas vegetarianas e não vegetarianas. O grupo que consumiu a suplementação de creatina melhorou a massa corporal livre de gorduras, por outro lado, o grupo que não consumiu creatina não teve aumento de massa muscular significativos.

No Quadro 1. Estudos com suplementação de creatina em praticantes de treinamento resistido idosos, está descrito alguns estudos realizados para verificar os principais efeitos e os benefícios da suplementação de creatina em praticantes de treinamento resistido em diferentes idosos.

Quadro 1. Estudos com suplementação de creatina em praticantes de treinamento resistido idosos.

\begin{tabular}{|c|c|c|c|}
\hline Autores & Público avaliado & Intervenção & Conclusão \\
\hline $\begin{array}{l}\text { (Aguiar, et } \\
\text { al., 2003) }\end{array}$ & $\begin{array}{l}18 \text { mulheres saudáveis }(64,9 \pm \\
5,0 \text { anos }) \\
\text { Grupo de suplementação com } \\
\text { creatina }(\mathrm{N}=9) \\
\text { Grupo Placebo }(\mathrm{N}=9)\end{array}$ & $\begin{array}{l}\text { Ambos os grupos foram } \\
\text { submetidos ao programa de } \\
\text { treinamento resistido de } 12 \\
\text { semanas ( } 3 \text { dias por semana), } \\
\text { consumindo uma quantidade } \\
\text { equivalente de creatina }(5,0 \\
\text { gramas por dia. }\end{array}$ & $\begin{array}{l}\text { Os autores relataram que a suplementação } \\
\text { de creatina em longo prazo combinada com } \\
\text { treinamento resistido melhora a capacidade } \\
\text { de realizar tarefas funcionais de força } \\
\text { submáxima e promove maior aumento na } \\
\text { força máxima, massa livre de gordura e } \\
\text { massa muscular em mulheres mais velhas. }\end{array}$ \\
\hline $\begin{array}{l}\text { (Alves, et al., } \\
\text { 2013) }\end{array}$ & $\begin{array}{l}\text { Participaram do estudo o } n=56 \\
\text { idosos } \\
\text { 1) placebo (n=14) } \\
\text { 2) suplementação de creatina } \\
(\mathrm{n}=14) \\
\text { 3) placebo associado ao } \\
\text { treinamento de força }(\mathrm{n}=14) \\
\text { 4) suplementação de creatina } \\
\text { associada ao treinamento de } \\
\text { força }(\mathrm{n}=14)\end{array}$ & $\begin{array}{l}\text { Este é um estudo de } 24 \text { semanas. } \\
\text { De acordo com sua alocação, os } \\
\text { participantes receberam creatina } \\
(4 \times 5 \text { gramas ao dia por } 5 \text { dias } \\
\text { seguida de } 5 \text { gramas ao dia) ou } \\
\text { placebo (dextrose na mesma } \\
\text { dosagem) e foram treinados ou } \\
\text { não com treinamento resistido, } \\
\text { conforme cada grupo. }\end{array}$ & $\begin{array}{l}\text { Os autores relataram que a suplementação } \\
\text { de creatina não promoveu nenhuma } \\
\text { mudança significativa na função cognitiva e } \\
\text { nos parâmetros emocionais em idosos } \\
\text { aparentemente saudáveis. Além disso, o } \\
\text { treinamento de força por si só melhorou o } \\
\text { estado emocional e a força muscular, mas } \\
\text { não a cognição, sem efeitos aditivos da } \\
\text { suplementação de creatina. }\end{array}$ \\
\hline $\begin{array}{l}\text { (Bemben et } \\
\text { al. 2010). }\end{array}$ & $\begin{array}{l}\mathrm{N}=42 \text { homens, } 48-72 \text { anos } \\
(\mathrm{N}=10) \text { Placebo treinado com } \\
\text { resistência } \\
(5 \text { gramas de creatina, } \mathrm{n}=10) \\
\text { Creatina e treinamento resistido } \\
\text { (35gramas de whey protein } \mathrm{n}= \\
\text { 11) Proteína e treinamento } \\
\text { resistido } \\
\text { (5gramas de creatina e } 35 \\
\text { gramas whey protein } \mathrm{n}=11) \\
\text { Creatina e Proteína Treinada por } \\
\text { Resistência }\end{array}$ & $\begin{array}{l}14 \text { semanas de treinamento de } \\
\text { resistência suplementado com } \\
\text { creatina ou proteína. }\end{array}$ & $\begin{array}{l}\mathrm{O} \text { treinamento de resistência em homens de } \\
\text { meia-idade e mais velhos aumentou } \\
\text { significativamente a força muscular e } \\
\text { acrescentou massa muscular sem benefícios } \\
\text { adicionais da suplementação de creatina ou } \\
\text { proteína. }\end{array}$ \\
\hline $\begin{array}{l}\text { (Chrusch, et } \\
\text { al., 2001). }\end{array}$ & $\begin{array}{l}\mathrm{N}=30 \text { homens } \\
\text { Grupo suplementado com } \\
\text { creatina }(\mathrm{N}=16, \text { idade }=70,4+/- \\
1,6 \text { anos }) \\
\text { Placebo }(\mathrm{N}=14, \text { idade }=71,1+/- \\
1,8 \text { anos })\end{array}$ & $\begin{array}{l}\text { Os grupos participaram de } \\
\text { treinamento de resistência ( } 36 \\
\text { sessões, } 3 \text { vezes por semana, } 3 \\
\text { séries de } 10 \text { repetições, } 12 \\
\text { exercícios). } \\
\text { A suplementação de creatina } \\
\text { consistiu em } 0,3 \text { gramas creatina } \\
x \text { peso corporal durante os } \\
\text { primeiros } 5 \text { dias e } 0,07 \mathrm{~g} \text { creatina } \\
\text { x o peso corporal }\end{array}$ & $\begin{array}{l}\text { A suplementação de creatina, associada ao } \\
\text { treinamento resistido aumenta a massa } \\
\text { muscular, melhora a força muscular, } \\
\text { melhora a resistência e a potência em } \\
\text { homens com a média idade de } 70 \text { anos. }\end{array}$ \\
\hline
\end{tabular}

Fonte: Autores. 
Bermon, et al., (1998), avaliaram os efeitos da suplementação com creatina em homens e mulheres mais velhos durante 8 semanas de treinamento resistido. A suplementação de creatina não evidenciou benefícios à composição corporal, através da estimação por dobras cutâneas, repetição máxima (1-RM), resistência dinâmica (12-RM) e resistência isométrica. Porém, deve-se observar que Bermon, et al., (1998), estudou quatro subgrupos não específicos de gênero (treinamento com creatina, treinamento com placebo, sem treinamento com creatina e sem treinamento com placebo) com baixo número de voluntários $(\mathrm{N}=8)$ podendo interferir nas diferenças significativas resultantes da suplementação com creatina associado ao treinamento resistido.

No entanto, dois estudos compararam as adaptações ao treinamento de supino e Leg Press em idosos do sexo masculino e relataram mudanças equivalentes na força para os dois exercícios avaliados. Porém, estas mudanças na resistência muscular do exercício de Leg Press (número máximo de repetições) foram maiores na resistência muscular do supino (Treuth, et al., 1994).

De acordo com Aguiar, et al., (2013), a suplementação de creatina a longo prazo, associado com o treinamento resistido, promove efeitos benéficos em mulheres mais velhas e relataram que a suplementação de creatina aumentou o volume de treinamento e o desempenho de uma repetição máxima (1RM) no supino, rosca bíceps e extensão de joelho; aumentou a eficiência na realização de testes funcionais de força submáxima (testes de levantar da cadeira, flexão de braço e levantar e deitar no chão por 30 s); promoveu maior aumento na massa livre de gordura e massa muscular.

Gotshalk, et al., (2008), descreveram que a suplementação de creatina a longo prazo tem o potencial de aumentar a força máxima em mulheres mais velhas, podendo levar o aumento da capacidade funcional e redução do risco de lesões. Embora melhorias na capacidade de realizar testes de força máxima sejam de interesse óbvio para populações jovens, porém, Canete, et al., (2006), cita que esses testes são de pouca relevância para prática em idosos.

Mihic, et al., (2000), observaram efeitos ergogênicos específicos de gênero para a suplementação de creatina em indivíduos jovens; relataram o aumento na massa corporal total para homens, no entanto, não para mulheres (homens: $+1,6 \mathrm{e}$ em mulheres: $+0,45 \mathrm{~kg}$ ) e observaram a forte tendência em direção a menor aumento na massa livre de gordura para mulheres (homens: $+1,3$ vs. mulheres: $+0,44 \mathrm{~kg}$ ) em resposta à suplementação de creatina por 5 dias. Isso foi relatado em estudo de Ferguson e Syrotuik (2006), que não encontraram nenhum efeito adicional da suplementação de creatina na força e massa corporal magra em mulheres experientes com treinamento de resistência, após um programa de treinamento resistido de 10 semanas associado a suplementação de creatina.

\section{Considerações Finais}

O consumo de creatina aumenta o estoque creatina muscular, auxiliando na recuperação muscular, após exercícios de alta intensidade, permitindo volume maior de treinamento. De acordo com a revisão realizada, demonstrou que a suplementação de creatina por praticantes de treinamento resistido poderá influenciar nos resultados fisiológicos, de tal maneira a melhorar a força muscular, a hidratação celular, o aumento de massa muscular e a resistência muscular. No entanto, os mesmos resultados apresentados para o sexo masculino não ocorrem no gênero feminino em tamanha proporção, e os homens praticantes de treinamento resistido da terceira idade não obtém os mesmos resultados que em homens mais jovens.

Após o levantamento bibliográficos realizados de natureza qualitativa, sugerimos para futuras pesquisas uma revisão sistematizada de natureza quantitativa, para que possa mensurar estatisticamente os resultados de estudos aplicados a voluntários em pesquisas com intervenção.

Após o levantamento bibliográficos realizados de natureza qualitativa, sugerimos para futuras pesquisas uma revisão sistematizada de natureza quantitativa, para que possa mensurar estatisticamente os resultados de estudos aplicados a 
voluntários em pesquisas com intervenção.

\section{Referências}

Aguiar, A. F., Januário, R. S. B., Junior, R. P., Gerage, A. M., Pina, F. L. C., Do Nascimento, M. A., \& Cyrino, E. S. (2013). Long-term creatine supplementation improves muscular performance during resistance training in older women. European journal of applied physiology, 113(4), 987-996.

Alves, C. R. R., Merege Filho, C. A. A., Benatti, F. B., Brucki, S., Pereira, R. M. R., de Sá Pinto, A. L., \& Gualano, B. (2013). Creatine supplementation associated or not with strength training upon emotional and cognitive measures in older women: a randomized double-blind study. PLoS One, 8(10), e76301.

Bemben, M. G., Witten, M. S., Carter, J. M., Eliot, K. A., Knehans, A. W., \& Bemben, D. A. (2010). The effects of supplementation with creatine and protein on muscle strength following a traditional resistance training program in middle-aged and older men. The journal of nutrition, health \& aging, $14(2), 155-159$.

Bermon, S., Venembre, P., Sachet, C., Valour, S., \& Dolisi, C. (1998). Effects of creatine monohydrate ingestion in sedentary and weight-trained older adults. Acta Physiologica Scandinavica, 164(2), 147-155.

Buford, T. W., Kreider, R. B., Stout, J. R., Greenwood, M., Campbell, B., Spano, M., \& Antonio, J. (2007). International Society of Sports Nutrition position stand: creatine supplementation and exercise. Journal of the International Society of Sports Nutrition, 4(1), 1-8.

Burke, D. G., Candow, D. G., Chilibeck, P. D., MacNeil, L. G., Roy, B. D., Tarnopolsky, M. A., \& Ziegenfuss, T. (2008). Effect of creatine supplementation and resistance-exercise training on muscle insulin-like growth factor in young adults. International journal of sport nutrition and exercise metabolism, 18(4), 389-398.

Cañete, S., San Juan, A. F., Pérez, M., \& Gómez-Gallego, F. (2006). Does creatine supplementation improve functional capacity in elderly women?. Journal of Strength and Conditioning Research, 20(1), 22.

Chrusch, M. J., Chilibeck, P. D., Chad, K. E., Davison, K. S., \& Burke, D. G. (2001). Creatine supplementation combined with resistance training in older men. Medicine \& Science in Sports \& Exercise, 33(12), 2111-2117.

Cooke, M. B., Rybalka, E., Williams, A. D., Cribb, P. J., \& Hayes, A. (2009). Creatine supplementation enhances muscle force recovery after eccentricallyinduced muscle damage in healthy individuals. Journal of the International Society of Sports Nutrition, 6(1), 1-11.

Cribb, P. J., Williams, A. D., \& Hayes, A. (2007). A creatine-protein-carbohydrate supplement enhances responses to resistance training. Medicine and Science in Sport and Exercise, 39(11), 1960-1968.

Dangott, B., Schultz, E., \& Mozdziak, P. E. (2000). Dietary creatine monohydrate supplementation increases satellite cell mitotic activity during compensatory hypertrophy. International journal of sports medicine, 21(01), 13-16.

Estrela, C. (2018). Metodologia Científica: Ciência, Ensino, Pesquisa. Editora Artes Médicas.

Ferguson, T. B., \& Syrotuik, D. G. (2006). Effects of creatine monohydrate supplementation on body composition and strength indices in experienced resistance trained women. Journal of strength and conditioning research, 20(4), 939.

Gotshalk, L. A., Kraemer, W. J., Mendonca, M. A., Vingren, J. L., Kenny, A. M., Spiering, B. A., \& Volek, J. S. (2008). Creatine supplementation improves muscular performance in older women. European journal of applied physiology, 102(2), 223-231.

Jakobi, J. M., Rice, C. L., Curtin, S. V., \& Marsh, G. D. (2000). Contractile properties, fatigue and recovery are not influenced by short-term creatine supplementation in human muscle. Experimental physiology, 85(4), 451-460.

Kreider, R. B., Kalman, D. S., Antonio, J., Ziegenfuss, T. N., Wildman, R., Collins, R., \& Lopez, H. L. (2017). International Society of Sports Nutrition position stand: safety and efficacy of creatine supplementation in exercise, sport, and medicine. Journal of the International Society of Sports Nutrition, 14(1), $1-18$.

Louis, M., Poortmans, J. R., Francaux, M., Hultman, E., Berré, J., Boisseau, N., \& Rennie, M. J. (2003). Creatine supplementation has no effect on human muscle protein turnover at rest in the postabsorptive or fed states. American Journal of Physiology-Endocrinology and Metabolism, 284(4), E764-E770.

Mihic, S., MacDonald, J. R., McKenzie, S., \& Tarnopolsky, M. A. (2000). Acute creatine loading increases fat-free mass, but does not affect blood pressure, plasma creatinine, or CK activity in men and women. Medicine and science in sports and exercise, 32(2), 291-296.

Persky, A. M., \& Brazeau, G. A. (2001). Clinical pharmacology of the dietary supplement creatine monohydrate. Pharmacological reviews, 53(2), 161-176.

Rawson, E. S., \& Volek, J. S. (2003). Effects of creatine supplementation and resistance training on muscle strength and weightlifting performance. The Journal of Strength \& Conditioning Research, 17(4), 822-831.

Safdar, A., Yardley, N. J., Snow, R., Melov, S., \& Tarnopolsky, M. A. (2008). Global and targeted gene expression and protein content in skeletal muscle of young men following short-term creatine monohydrate supplementation. Physiological genomics, 32(2), $219-228$.

Treuth, M. S., Ryan, A. S., Pratley, R. E., Rubin, M. A., Miller, J. P., Nicklas, B. J., \& Hurley, B. F. (1994). Effects of strength training on total and regional body composition in older men. Journal of applied physiology, 77(2), 614-620.

Volek, J. S., \& Rawson, E. S. (2004). Scientific basis and practical aspects of creatine supplementation for athletes. Nutrition, 20(7-8), 609-614.

Volek, J. S., \& Kraemer, W. J. (1996). Creatine supplementation: its effect on human muscular performance and body composition. The Journal of Strength \& Conditioning Research, 10(3), 200-210.

Wyss, M., \& Kaddurah-Daouk, R. (2000). Creatine and creatinine metabolism. Physiological reviews, 80(3), 1107-1213. 